\title{
Las habilidades socio-emocionales para la mediación escolar: una revisión sistemática
}

\section{Socio-emotional skills for peer mediation: a sistematic review}

\author{
Francisco Javier Benítez Moreno' \\ Harvey Mauricio Herrera-López² \\ Universidad de Nariño
}

Antonio J. Rodríguez-Hidalgo ${ }^{3}$

Universidad de Córdoba

\section{RESUMEN}

Las cualidades personales, sociales y emocionales del mediador parecen facilitar la posibilidad de cambiar las dinámicas del conflicto, pues facilitan formas prosociales de solución que

1 Psicólogo, Universidad de Nariño. Magister en Musicoterapia, Universidad Nacional de Colombia. Candidato a doctor en Ciencias de la Educación, RUDECOLOMBIA. Docente con funciones de orientador en Secretaría de Educación Municipal de Pasto. Investigador grupo psicología y salud. Contacto: javierbenitez07@gmail.com

2 Psicólogo, Universidad de Nariño. Magister en Educación, Universidad de Nariño. Doctor en Ciencias Sociales y Jurídicas, Universidad de Córdoba (España). Profesor Asociado, Departamento de Psicología, Universidad de Nariño (Colombia). Investigador grupo psicología y salud. Orcid.org/0000-0002-0292-2688 Contacto: mherrera@ude$\underline{\text { nar.edu.co }}$

3 Licenciado en Psicopedagogía, Universidad de Córdoba. Doctor en Psicología Aplicada, Universidad de Córdoba. Profesor Contratado Doctor, Departamento de Psicología, Universidad de Córdoba (España). Orcid. org/0000-0001-6968-8665 Contacto: ajrodriguez@uco.es aportan a la construcción de la cultura de paz en la escuela. El presente estudio tiene como objetivo identificar los elementos teóricos que constituyen las habilidades socio-emocionales para la mediación escolar. Se realizó una revisión sistemática cualitativa soportada en el protocolo PRISMA que incluyó 38 documentos académicos. El análisis permitió identificar las dimensiones del constructo, las cuales son habilidades para: 1) la conciencia y regulación emocional, 2) la comprensión y gestión del conflicto y 3) la facilitación de la comunicación. El aporte al cuerpo teórico del estudio del conflicto sirve de fundamento para la creación de instrumentos de medición, así como también ayuda a conformar el equipo de mediadores y a promover programas de formación orientados a 
fortalecer la capacidad de atender con destreza situaciones de incompatibilidad de intereses.

\section{PALABRAS CLAVE:}

Habilidades sociales, emociones, mediación escolar, convivencia escolar, cultura de paz.

\section{ABSTRACT}

The personal qualities of the mediator seem to facilitate the possibility of changing the dynamics of the conflict since it facilitates prosocial forms of solution that contribute to the construction of a culture of peace in the school. The present study aims to identify the theoretical elements that constitute socio-emotional skills for school mediation. A systematic qualitative review supported by the PRISMA protocol was carried out which included 38 academic papers. The analysis allowed identifying the dimensions of the construct, which are skills for: 1) emotional awareness and regulation, 2) understanding and managing conflict, and 3) facilitating communication. The contribution to the theoretical body of the study of the conflict serves as the foundation for the creation of measurement instruments, as well as it helps to form the team of mediators and promote training programs for school mediators focused on strengthening the ability to skillfully address situations of incompatibility of interests.

\section{KEYWORDS:}

Social skills, emotions, peer mediation, peaceful coexistence, culture of peace.

\section{RESUMO}

As qualidades pessoais, sociais e emocionais do mediador parecem facilitar a possibilidade de mudança da dinâmica do conflito, pois facilitam formas de solução pró-social que contribuem para a construção de uma cultura de paz na escola. O presente estudo tem como objetivo identificar os elementos teóricos que constituem as competências socioemocionais para a mediação escolar. Uma revisão sistemática qualitativa apoiada pelo protocolo PRISMA foi realizada que incluiu 38 artigos acadêmicos. A análise identificará as dimensões do construto, que são habilidades para: 1) consciência e regulação emocional, 2) compreensão e gerenciamento de conflitos e 3) facilitar a comunicação. A contribuição do referencial teórico do estudo do conflito serve de base para a criação de instrumentos de medicação, além de auxiliar na formação da equipe de mediadores e promover programas de capacitação que visem fortalecer a capacidade de atendimento a competências de interesses incompatíveis.

PALAVRAS-CHAVE: Habilidades sociais, emoções, mediação de pares, coexistência pacífica, cultura de paz.

\section{INTRODUCCIÓN}

La mediación escolar es una estrategia educativa mediante la cual se pretende resolver el conflicto de manera que resulte satisfactoria para las partes a través del diálogo (Cava, 2009; Caycedo y Cocunubo, 2016; Gonzáles, 2018; Hermosilla, 2015; Lungman, 1996; Ortega y Del Rey, 2006; Ortega et al., 2007; Pulido et al., 2010; Rolán et al., 2017; Zambrano, 2015), por tanto, las habilidades sociales y emocionales de un mediador tienen relevancia en la posibilidad de lograr entendimiento entre las partes. El presente estudio se orienta hacia la revisión sistemática de la literatura científica relacionada con las habilidades socio-emocionales del mediador, actor fundamental en el propósito de cambiar la perspectiva del conflicto, hacia la búsqueda de formas prosociales de solución que aporten a la cultura de paz.

\section{CONFLICTO Y MEDIACIÓN ESCOLAR}

En las relaciones interpersonales de los iguales en la escuela se producen situaciones en donde se contraponen intereses que pugnan por un 
mismo objetivo, configurándose así el conflicto, que se puede definir como una interacción en la que dos o más personas entran en oposición, confrontación o desacuerdo y emprenden acciones mutuamente antagonistas (Benavides, 2013; Betancourth, Carvajal y Figueroa, 2013; Chaux y Velázquez, 2008). El conflicto es considerado inevitable y consustancial en las relaciones humanas y en él participan las diferencias personales y las condiciones del contexto de interacción; no obstante, su connotación predominantemente negativa, también puede tener efectos positivos para estimular la creatividad (Cabrera, García y Tabares, 2016). En consecuencia, la mediación es la estrategia que se considera indicada para resolver los conflictos; esta se define como un proceso voluntario en la que las dos partes enfrentadas, recurren a una tercera "imparcial" (mediador), para lograr acuerdos satisfactorios. Este proceso se caracteriza por ser cooperativo, extrajudicial, creativo y motivado por el deseo de una óptima convivencia en un contexto social (Holaday, 2002). Si bien hay diversas clasificaciones, en general, se reconocen 4 tipos de mediación: a) normativa-evaluativa, b) racional-analítica, c) terapéutica, y d) educativa (de Armas, 2003), esta última de la que se ocupa el presente estudio.

Las estrategias de mediación escolar pretenden que las personas tomen distancia de las emociones negativas que suscita un conflicto, se concentren en los intereses no en las posiciones, y generen opciones y alternativas para que ambos superen la situación percibiendo ganancia (Gonzáles, 2018). Dado que la mediación es un acto voluntario, de libre composición y confidencial (Caycedo y Cocunubo, 2016; Pulido et al., 2010), se requiere que el mediador se apropie del conflicto, analice la complejidad del tema, escuche por igual las versiones de las partes para encontrar fórmulas de acuerdos y aprendizajes que permitan transformar el modo en que se relacionan, mejorando así la convivencia (Caycedo y Cocunubo, 2016; Ortega et al., 2007). El propósito de la mediación es solventar las diferencias mediante el diálogo, la concertación, el reconocimiento de la diferencia en la ética del cuidado de los demás (Candeias y Bartolo, 2016); también contribuye con el establecimiento de una cultura de paz en la escuela (Cano y Garrido, 2017; Pinto, 2017). Entre otros beneficios, permite mejorar el clima escolar y cooperar con la consecución de sociedades más respetuosas de la diversidad humana (Viana y López, 2015), en tanto genera competencias que pueden transferirse más allá de los límites escolares (García et al., 2015). Así mismo, la mediación ayuda a disminuir la tensión y la hostilidad, promueve el desarrollo de competencias sociales, liderazgo, pensamiento crítico, la capacidad reflexiva y las habilidades de solución de problemas; también incrementa la participación de los estudiantes, fortalece la autoestima y la práctica de valores (Díaz et al., 2015; Lungman, 1996).

La mediación representa una gran ventaja para las instituciones educativas, pues es la manera más adecuada de solucionar situaciones como ofensas verbales y físicas, agresiones, robos, entre otras (Benavides, 2013; Betancourth, et al., 2017; Chaux y Velázquez, 2008), que en muchas ocasiones no se abordan de forma adecuada por docentes y directivos (Benavides, 2013; Castro, 2013). De ahí la necesidad de trabajar en la implementación de la mediación como alternativa para superar los conflictos y resolver las diferencias, y que en general beneficia la convivencia escolar (Villanueva, 2013; Vizcaíno, 2015; Torrego, 2008 citado en Ibarrola e Iriarte, 2014).

\section{HABILIDADES SOCIO-EMOCIONALES EN LA MEDIACIÓN ESCOLAR.}

Inicialmente es necesario aludir al concepto de habilidad. Bermúdez y Rodríguez (2019) la definen como la acción plenamente dominada; Portillo (2017), sugiere que es la capacidad 
de adaptación a los retos del contexto; por su parte Dorsch, Bergius y Ries (1996), la definen como la capacidad de resolver determinados problemas y no se limita a la mera disposición y aptitud, sino que incluye la facultad de ejecutar del mejor modo posible, con destreza y dominio. En consecuencia, se puede asumir como el despliegue de comportamientos con dominio (buena ejecución) y destreza, que influyen de modo decisivo en el logro o consecución de una meta en un contexto o demanda en particular (Serrano et al., 2007).

Si bien no se reconocen estudios que analicen de manera precisa las habilidades que debe tener una persona para cumplir una tarea de mediación escolar, existen algunas aproximaciones que se consideran referentes para avanzar en la concepción de este constructo (Jhonson et al., 1996; López, 2016; Serrano y Méndez, 1999 Serrano et al., 2007; Zambrano, 2015). Méndez (1994 citado en Serrano y Méndez, 1999) clasifica las habilidades de mediación en tres grupos: a) personales (comunicación, asertividad, empatía), b) intelectuales (inteligencia, creatividad), c) técnicas (conocimientos del problema, entrenamiento). En la misma línea, Johnson et al. (1996), las categoriza en: a) básicas de comunicación (envío de mensajes, escucha activa, reflexión de sentimientos), b) de asertividad y c) de mediación. Serrano et al. (2007) sugiere que son destrezas relacionadas con la satisfacción y la eficacia de la mediación; desde esta perspectiva las agrupa en un primer momento en: confianza y credibilidad, firmeza en sus propuestas y opiniones, actitud conciliadora, comprensión de los intereses de ambos; luego propone un segundo grupo en donde se encuentran: conocimientos y formación, promoción del aumento de la confianza entre las partes, capacidad de realizar sugerencias para facilitar el acuerdo, y ayuda para la clarificación de asuntos importantes.

Recientemente López (2016), propone tres grupos de habilidades para la mediación: a) emocionales, b) cognitivas y c) de conducta. En las primeras, el mediador debe ser capaz de identificar todo el rango de emociones que están experimentando las personas en conflicto durante las sesiones (Zambrano, 2015); en las segundas, se espera que disponga de habilidades para examinar las propias creencias que pueden influir en tomar partido, así como también tener la capacidad para validar las perspectivas e integrarlas (Zambrano, 2015); y en las terceras, el mediador debe ser un excelente observador y dominar la comunicación verbal y no verbal (Zambrano, 2015) que implica comunicarse a través del contacto visual, la expresividad facial, el tono de voz, algunas señales verbales como hacer pedidos claros, y responder eficazmente a la crítica (López, 2016).

$\mathrm{Si}$ bien se reconocen algunos avances en el cuerpo teórico de conocimiento sobre las habilidades para la mediación escolar, se requiere continuar con su delimitación en el contexto escolar, en procura de una mejor conceptualización, especialmenteenlaformación de estas habilidades socio-emocionales para la mediación escolar. Esto ofrecerá beneficios para el desarrollo de instrumentos de evaluación tendientes a la selección de mediadores, y para la organización de programas de formación de mediadores escolares. En coherencia con lo anterior, el presente estudio tiene como objetivo identificar los elementos teóricos que constituyen la formación de habilidades socioemocionales para la mediación escolar, a partir de una revisión sistemática en cinco de las más reconocidas bases bibliográficas.

\section{MÉTODO}

\section{Unidad de Análisis}

Se analizaron 38 artículos que abordaron aspectos relacionados con el estudio de habilidades para la mediación escolar, encontrados en las bases de datos: Scopus, 
Ebsco Host, Redalyc, Eric y Google Académico. Estas bases de datos se escogieron por su reconocido y amplio uso científico, además de proveer diversidad de documentos indexados, investigaciones y reflexiones teóricas relevantes para el estudio.

\section{INSTRUMENTOS}

Para la gestión documental se utilizó una matriz soportada en el protocolo PRISMA (Moher et al., 2015), recomendado para el desarrollo de revisiones sistemáticas. La matriz se aplicó a cada uno de los artículos registrando: autores, título del artículo, base de datos de la que fue recuperado, tipo de texto (capítulo de libro, tipo de artículo, tesis doctoral), país, año, resumen y observaciones relacionadas con el constructo "habilidades para la mediación escolar".

\section{DISEÑO Y PROCEDIMIENTO}

Este estudio es de tipo analítico-documental, a partir de la revisión sistemática (Montero y León, 2007). La búsqueda se realizó utilizando entre comillas la palabra o frase clave: habilidades para la mediación escolar en idioma castellano, inglés (school mediation skills - peer mediation skills) y en portugués (habilidades de mediação escolar - habilidades de mediação entre pares); también se usaron operadores booleanos (relacionales y de posición): "+", "\&”, "|", “XOR”, "_", "SAME”, "WITH”, "NEAR", "FAR", "ADJ". Los resultados fueron probados en el intervalo 1995 a 2020.

Los criterios de elección fueron, en primer lugar: el título, resumen y palabras clave de cuentas de la mediación en el ámbito educativo; y segundo, que el contenido aborde el concepto de habilidades para la mediación escolar. Se incluyeron: artículos, capítulos de libro, tesis de posgrado (maestría y doctorado). Se estableció filtro de duplicados y se procedió a la lectura completa de los artículos finalmente seleccionados.

\section{RESULTADOS}

La selección se realizó siguiendo el flujograma propio de la metodología PRISMA (ver figura 1). La muestra final del estudio quedó constituida por 38 documentos.

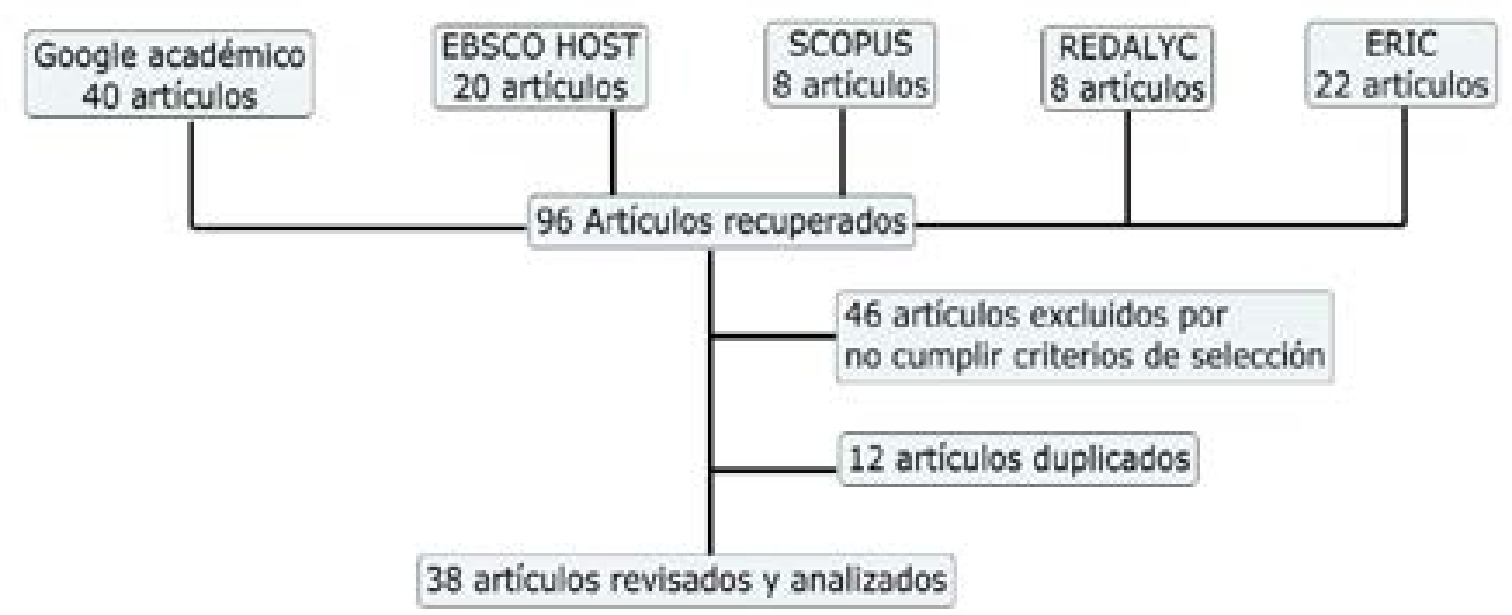

Figura 1. Flujograma de la revisión sistemática en las bases de datos. 
Respecto al país de origen de la publicación, se reconoce que España lidera la producción científica en la temática con el $58 \%(n=22)$, le sigue Estados Unidos, con 16\% ( $n=13)$, y Turquía con $8 \%(n=3)$ (Ver figura 2).

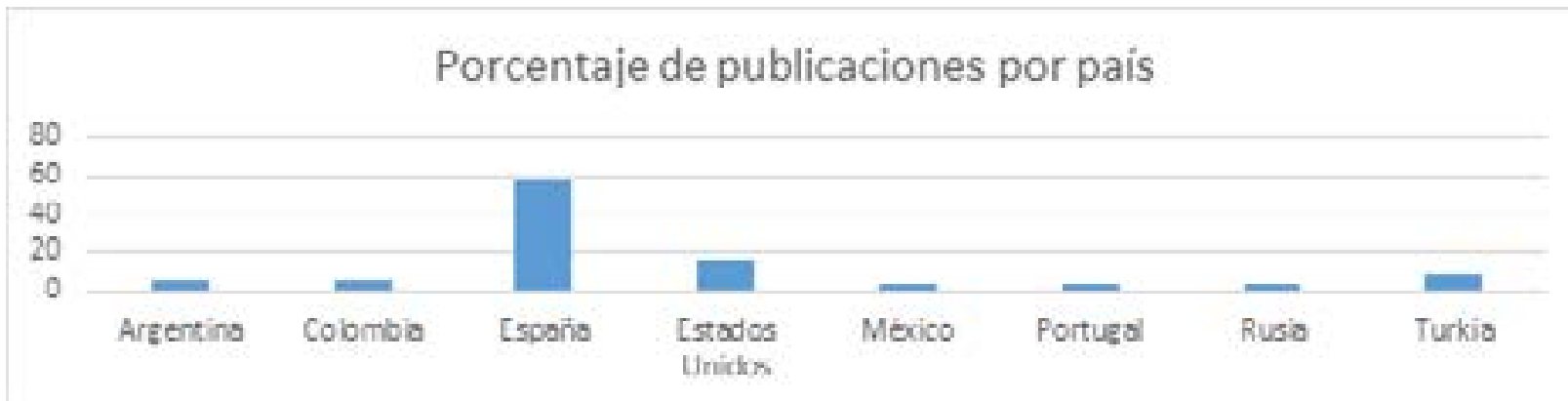

Figura 2. Porcentaje de publicaciones por país.

En referencia al número de publicaciones por año, esta permanece constante entre 1995 y 2014, a partir de 2015 se observa un interés creciente en la temática, siendo el año 2017 el de mayor publicación.

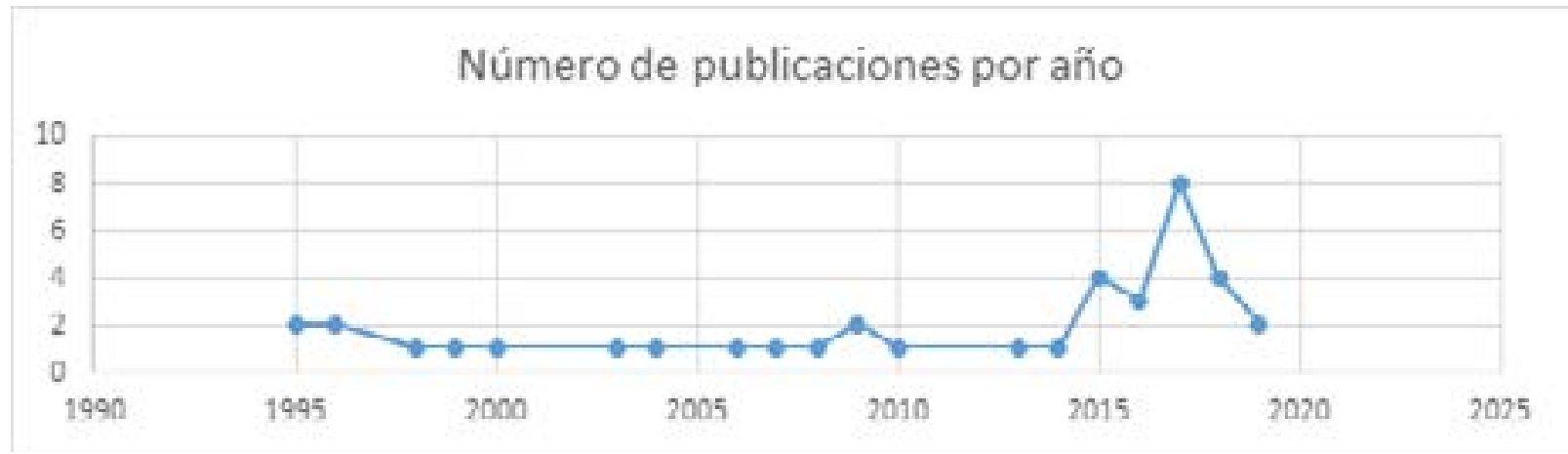

Figura 3. Número de publicaciones por año entre 1995 y 2020.

Respecto al tipo de documento, el $52 \%$ corresponde a artículos no derivados de investigación $(n=20)$, el $42 \%$ son artículos de investigación $(n=16)$. Se encontró una tesis doctoral y un capítulo de libro. De otro lado, se identifica que los trabajos van en línea con: 1) la naturaleza del constructo, y 2 ) sus dimensiones, identificadas como habilidades para la conciencia y regulación emocional, comprensión y gestión del conflicto, facilitación de la comunicación. A continuación, se presenta una síntesis de los principales aportes realizados al constructo y a cada uno de sus componentes. 
Tabla 1. Principales aportes realizados al constructo Habilidades para la Mediación Escolar (HME).

\begin{tabular}{|c|c|c|}
\hline Autor/año & Título/tipo de documento & Aportes al Constructo \\
\hline $\begin{array}{l}\text { Acosta, R. y } \\
\text { Arboleda, A. } \\
\text { (2019). }\end{array}$ & $\begin{array}{l}\text { La educación en mediación } \\
\text { escolar como escenario de } \\
\text { formación ciudadana. } \\
\text { Artículo de reflexión. }\end{array}$ & $\begin{array}{l}\text { El conflicto se aborda no solo desde el referente legal } \\
\text { sino teniendo en cuenta a la persona, sus emociones } \\
\text { y sentimientos ya que el logro de los acuerdos } \\
\text { se obtiene por la habilidad y orientación que a la } \\
\text { audiencia le imprime el conciliador. }\end{array}$ \\
\hline $\begin{array}{l}\text { Aznar, J., } \\
\text { Castillo, L., } \\
\text { Duplá, T. } \\
\text { (2018). }\end{array}$ & $\begin{array}{l}\text { Técnicas de mediación } \\
\text { en educación secundaria } \\
\text { deberían tener en cuenta } \\
\text { diferencias de género para } \\
\text { alcanzar efectividad. } \\
\text { Artículo de investigación. }\end{array}$ & $\begin{array}{l}\text { Las habilidades de resolución de conflictos son: } \\
\text {-Comunicación. } \\
\text {-Empatía. } \\
\text {-Trabajo en equipo. }\end{array}$ \\
\hline $\begin{array}{l}\text { Ceviker, S., } \\
\text { Kagan, H., y } \\
\text { Akilli, M. } \\
\text { (2019). }\end{array}$ & $\begin{array}{l}\text { Examining the effects } \\
\text { of negotiation and peer } \\
\text { mediation on student's conflict } \\
\text { resolution and problem- } \\
\text { solving skills. } \\
\text { Artículo de investigación. }\end{array}$ & $\begin{array}{l}\text { Los programas de mediación tienen cuatro áreas: } \\
\text { comprensión de la naturaleza de los conflictos, } \\
\text { habilidades de comunicación, habilidades de manejo } \\
\text { de la ira, habilidades de resolución. }\end{array}$ \\
\hline $\begin{array}{l}\text { Ibarrola, S., } \\
\text { e Iriarte, C. } \\
\text { (2014). }\end{array}$ & $\begin{array}{l}\text { Empoderamiento } \\
\text { socioemocional a través de } \\
\text { mediación para resolver los } \\
\text { conflictos en una manera } \\
\text { cívica. } \\
\text { Artículo de investigación. }\end{array}$ & $\begin{array}{l}\text { La mediación promueve el desarrollo: } \\
\text {-Emocional: Asertividad, autoconsciencia, } \\
\text { autorregulación y empatía. } \\
\text {-Sociocognitivo: pensamiento reflexivo, conocimiento } \\
\text { de resolución de conflictos, técnicas de comunicación. } \\
\text {-Sociomoral: Respeto y reciprocidad, responsabilidad, } \\
\text { razonamiento moral y toma de decisiones. }\end{array}$ \\
\hline $\begin{array}{l}\text { Turnuklu, A., } \\
\text { et al. } \\
\text { (2010). }\end{array}$ & $\begin{array}{l}\text { The effects of conflict } \\
\text { resolution and peer mediation } \\
\text { training on Turkish elementary } \\
\text { school student's conflict } \\
\text { resolution strategies. Artículo } \\
\text { de investigación. }\end{array}$ & $\begin{array}{l}\text { Entre las habilidades se encuentran: } \\
\text {-Comprensión de la naturaleza de los conflictos } \\
\text { interpersonales. } \\
\text {-La comunicación. } \\
\text {-El manejo de la ira. } \\
\text {-La negociación y mediación de pares. }\end{array}$ \\
\hline $\begin{array}{l}\text { Serrano, G. } \\
\text { y Méndez, } \\
\text { M. (1999). }\end{array}$ & $\begin{array}{l}\text { Las intervenciones de los } \\
\text { mediadores. } \\
\text { Artículo de reflexión. }\end{array}$ & $\begin{array}{l}\text { Las habilidades se clasifican en tres grupos: } \\
\text { personales (comunicación, asertividad, empatía), } \\
\text { intelectuales (inteligencia, creatividad), técnicas } \\
\text { (conocimientos del problema, entrenamiento). }\end{array}$ \\
\hline
\end{tabular}




\begin{tabular}{|c|c|c|}
\hline $\begin{array}{l}\text { Serrano, G., } \\
\text { et al. } \\
(2007) \text {. }\end{array}$ & $\begin{array}{l}\text { Características de los } \\
\text { mediadores y éxito de la } \\
\text { mediación. } \\
\text { Artículo de investigación. }\end{array}$ & $\begin{array}{l}\text { Las habilidades son: Comprensión de la naturaleza de } \\
\text { los conflictos interpersonales, comunicación, manejo } \\
\text { de la ira, negociación y mediación de pares. }\end{array}$ \\
\hline $\begin{array}{l}\text { López, M. } \\
\text { (2016). }\end{array}$ & $\begin{array}{l}\text { Formación de formadores y } \\
\text { mediadores escolares con } \\
\text { análisis transaccional. } \\
\text { Artículo de reflexión. }\end{array}$ & $\begin{array}{l}\text { Distingue tres grupos principales de habilidades } \\
\text { para la mediación: las emocionales, cognitivas y de } \\
\text { conducta. }\end{array}$ \\
\hline $\begin{array}{l}\text { Jhonson, D. } \\
\text { et al. } \\
\text { (1996) }\end{array}$ & $\begin{array}{l}\text { Effectiveness of conflict } \\
\text { managers in an Inner-city } \\
\text { elementary school. } \\
\text { Artículo de investigación. }\end{array}$ & $\begin{array}{l}\text { Clasifica las habilidades en comunicación (envío de } \\
\text { mensajes, escucha activa, reflexión de sentimientos), } \\
\text { asertividad y mediación. }\end{array}$ \\
\hline $\begin{array}{l}\text { Candeias, } \\
\text { E. y Bartolo, } \\
\text { S. } \\
\text { (2016). }\end{array}$ & $\begin{array}{l}\text { La gravitación de la ética de } \\
\text { la mediación: intervención } \\
\text { social y escolar en las } \\
\text { escuelas. } \\
\text { Artículo de reflexión. }\end{array}$ & $\begin{array}{l}\text { Propone el modelo de resolución de problemas; la } \\
\text { mediación transformadora centrada en las relaciones } \\
\text { interpersonales donde se aboga por un crecimiento } \\
\text { personal; la comunicacional focalizada en las } \\
\text { relaciones y en los acuerdos. El proceso es más } \\
\text { importante que el resultado. }\end{array}$ \\
\hline $\begin{array}{l}\text { Leonov, N. y } \\
\text { Glavatskikh, } \\
\text { M. } \\
\text { (2017). }\end{array}$ & $\begin{array}{l}\text { Changing the image of a } \\
\text { conflict situation while training } \\
\text { school students in mediation } \\
\text { skills. } \\
\text { Artículo de investigación. }\end{array}$ & $\begin{array}{l}\text { Propone un programa de capacitación en mediación } \\
\text { para estudiantes basado en el enfoque ontológico, lo } \\
\text { que significa la habilidad para cambiar la perspectiva } \\
\text { del conflicto a través de la capacidad reflexiva y } \\
\text { comunicativa. }\end{array}$ \\
\hline $\begin{array}{l}\text { Daunic, A. } \\
\text { et al. } \\
(2000) \text {. }\end{array}$ & $\begin{array}{l}\text { School-wide conflict } \\
\text { resolution and peer mediation } \\
\text { programs: experiences in } \\
\text { three middle schools. } \\
\text { Artículo de reflexión. }\end{array}$ & $\begin{array}{l}\text { Se diseña un programa de formación en mediación de } \\
\text { pares cuyas actividades incluyen entendimiento del } \\
\text { conflicto, comunicación efectiva y manejo de la ira. }\end{array}$ \\
\hline $\begin{array}{l}\text { Brewer, B. } \\
\text { (1998). }\end{array}$ & $\begin{array}{l}\text { The effects of conflict } \\
\text { mediation training on } \\
\text { attitudes toward conflict and } \\
\text { interpersonal problem-solving } \\
\text { strategies on middle school. } \\
\text { Tesis doctoral. }\end{array}$ & $\begin{array}{l}\text { Las habilidades de mediación de conflictos incluyen } \\
\text { comunicación verbal y no verbal, escucha, resolución } \\
\text { de problemas, pensamiento crítico, toma de } \\
\text { decisiones y negociación. El programa de resolución } \\
\text { de conflictos utiliza destrezas de comunicación y } \\
\text { resolución de problemas para desarrollar alternativas } \\
\text { que eviten la escalada. }\end{array}$ \\
\hline
\end{tabular}

En la tabla uno, las habilidades para la mediación escolar son una labor más allá de un procedimiento legal; un arte fundamentado en la ética de la ayuda (Candeias y Bartolo, 2016). Las habilidades tienen que ver con las cualidades personales, la capacidad para generar confianza, el ingenio y perspicacia, están enfocadas al logro de la mediación (Acosta y Arboleda, 2019; Serrano y Méndez, 1999) entendido como la posibilidad de cambiar la perspectiva del conflicto (Leonov y Glavatskikh, 
2017). Se trata de patrones de comportamiento que adquieren sentido en una situación de mediación e influyen de manera decisiva en el éxito de esta (Serrano et al., 2007).

Las habilidades son: comunicación, escucha activa, asertividad, empatía, manejo de la ira, comprensión de la naturaleza de los conflictos interpersonales, solución de problemas y trabajo en equipo (Aznar et al., 2018; Ceviker et al., 2019; Daunic et al., 2000; Jhonson et al., 1996; Turnuklu et al., 2010; Yvetta et al., 1995). Por su parte, Ibarrola e Iriarte (2014) reconocen la dimensión emocional e integran la autoconciencia y la autorregulación, así como también los factores socioemocionales dados por el respeto y reciprocidad (entendimiento de la diversidad, actitudes cooperativas), responsabilidad (rol activo en la búsqueda de compromisos y reconciliación), razonamiento moral y toma de decisiones (transición de una perspectiva egocéntrica a una perspectiva moral). Mientras que Serrano y Méndez (1999) y Serrano et al. (2007) incluyen las habilidades técnicas o de conocimientos de la mediación. De acuerdo con López (2016) las habilidades se clasifican en tres grandes grupos según canal de respuesta: emociones, pensamientos y conductas.

Tabla 2. Principales aportes realizados a la dimensión Habilidades para la Conciencia y Regulación Emocional (CRE).

\begin{tabular}{|c|c|c|}
\hline Autor/año & Título/ tipo de documento & Aportes al constructo \\
\hline $\begin{array}{l}\text { Lungman, S. } \\
\text { (1996). }\end{array}$ & $\begin{array}{l}\text { La mediación escolar. } \\
\text { Capítulo de libro. }\end{array}$ & $\begin{array}{l}\text { Sensibilidad, toma de conciencia de } \\
\text { sí mismo, sentido del humor. }\end{array}$ \\
\hline $\begin{array}{l}\text { Sánchez, F. y } \\
\text { Gonzáles, E. } \\
(2017) \text {. }\end{array}$ & $\begin{array}{l}\text { Los programas de mediación escolar } \\
\text { como herramientas para la promoción } \\
\text { de unas relaciones de pareja } \\
\text { saludables en la adolescencia. } \\
\text { Artículo de reflexión. }\end{array}$ & $\begin{array}{l}\text { Toma de perspectiva, ponerse en el } \\
\text { lugar del otro. } \\
\text { a) Habilidades emocionales para } \\
\text { evitar actuar de forma inapropiada. }\end{array}$ \\
\hline $\begin{array}{l}\text { Cava, J. } \\
\text { (2009). }\end{array}$ & $\begin{array}{l}\text { La utilidad de la mediación como } \\
\text { estrategia de resolución y prevención } \\
\text { de conflictos. } \\
\text { Artículo de reflexión. }\end{array}$ & Empatía. \\
\hline $\begin{array}{l}\text { Ortega, R., } \\
\text { Rey, R. } \\
(2006) .\end{array}$ & $\begin{array}{l}\text { La mediación escolar en el marco de } \\
\text { la construcción de la convivencia y } \\
\text { prevención de la violencia. }\end{array}$ & $\begin{array}{l}\text { Empatía, tolerancia ante los } \\
\text { sentimientos de los demás. }\end{array}$ \\
\hline $\begin{array}{l}\text { Cuesta, M., et } \\
\text { al. } \\
(2017) \text {. }\end{array}$ & $\begin{array}{l}\text { El educador social en la enseñanza } \\
\text { secundaria. La mediación escolar como } \\
\text { alternativa de resolución de conflictos. } \\
\text { Artículo de reflexión. }\end{array}$ & $\begin{array}{l}\text { Sensibilidad ante los conflictos, } \\
\text { empatía, expresión de emociones y } \\
\text { sentimientos. }\end{array}$ \\
\hline
\end{tabular}


Romero, L., Mediación escolar en el modelo

Alamilla, M. y educativo para la educación obligatoria

García, J. en México.

(2017). Artículo de reflexión.

García, L., Bo Significado y sentido de la mediación

Bonet, R. y escolar desde la perspectiva del

Mondragón, J. alumnado mediador de secundaria.

(2018).

Artículo de investigación.

Olmos, S., Competencias profesionales en

Torrecilla, E. y resolución de conflictos: Eficacia de un

Rodríguez, M. programa para la mejora competencial.
Expresión, regulación y gestión de

emociones, reconocimiento de las causas y efectos de la expresión emocional.

\section{Capacidad para comprender el punto} de vista de los demás. \\ Artículo de investigación. $(2017)$}

Caycedo, R. y La mediación como una solución

Cocunubo, N. alternativa de la violencia escolar.

(2016). Artículo de investigación.

\begin{tabular}{lll}
\hline Turk, Fulya & Evaluation of the effects of conflict & Habilidades de consciencia cultural y \\
(2018). & resolution, peace education and peer & $\begin{array}{l}\text { empatía. } \\
\text { mediation: a meta-analysis study }\end{array}$
\end{tabular}

mediation: a meta-analysis study.

Artículo de investigación
Competencias para el autocontrol personal: regulación de los sentimientos, reconocer los de los demás, responder adecuadamente, adquirir destrezas para la dirección de situaciones de estrés y tensión. Capacidad de trabajo bajo presión, emprendedor, líder para tramitar las situaciones de tensión.

Ceviker, S., Examining the effects of negotiation Gestión de la ira.

Kagan, $H_{\text {., }} \quad y$ and peer mediation on student's conflict

Akilli, M. resolution and problem-solving skills.

(2019). Artículo de investigación.

Ibarrola, S., Aprendizaje emocional autoconsciente Es importante la conciencia y

Iriarte, C. y durante procedimientos de mediación regulación de emociones. Así mismo,

Aznáres, M. en el contexto escolar. la tolerancia.

(2017). $\quad$ Artículo de investigación.

\begin{tabular}{|c|c|c|}
\hline $\begin{array}{lr}\text { Lozano, } & \text { A., } \\
\text { Gutiérrez, } & \text { P. } \\
\text { y Martínez, } & \text { R. } \\
\text { (2018). } & \end{array}$ & $\begin{array}{l}\text { La mediación educativa como cultura } \\
\text { de paz. } \\
\text { Artículo de reflexión. }\end{array}$ & $\begin{array}{l}\text { Empatía, reconocimiento de } \\
\text { emociones. }\end{array}$ \\
\hline $\begin{array}{l}\text { Lorente, I. y } \\
\text { Torrego, J. } \\
\text { (2017). }\end{array}$ & $\begin{array}{l}\text { Percepción del alumnado y profesorado } \\
\text { sobre un programa de mediación entre } \\
\text { iguales. } \\
\text { Artículo de investigación. }\end{array}$ & Empatía y actitud de ayuda. \\
\hline
\end{tabular}




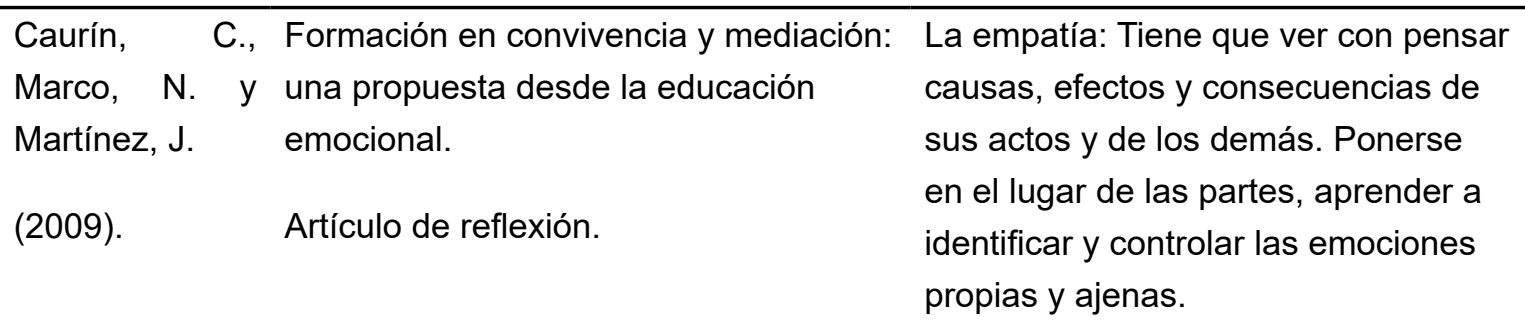

Caravaca, C. y La mediación herramienta para la

Empatía y flexibilidad.

Sáez, J. (2013). gestión de conflictos en la escuela.

Artículo de reflexión.

\begin{tabular}{|c|c|c|}
\hline $\begin{array}{l}\text { Medina, M. } \\
\text { (2015). }\end{array}$ & $\begin{array}{l}\text { Mediación entre pares en las escuelas } \\
\text { públicas: una alternativa para la } \\
\text { solución de conflictos. } \\
\text { Artículo de reflexión. }\end{array}$ & $\begin{array}{l}\text { Reducir la tensión individual, no } \\
\text { involucrarse afectivamente ni } \\
\text { prejuzgar. }\end{array}$ \\
\hline $\begin{array}{l}\text { Zambrano, R. } \\
\text { (2015). }\end{array}$ & $\begin{array}{l}\text { Implantación de un programa de } \\
\text { mediación escolar. } \\
\text { Artículo de reflexión. }\end{array}$ & $\begin{array}{l}\text { Ser capaz de identificar todo el } \\
\text { rango de emociones que están } \\
\text { experimentando las personas en } \\
\text { conflicto durante la mediación. }\end{array}$ \\
\hline $\begin{array}{l}\text { Cáceres, S., } \\
\text { Giménez, M. y } \\
\text { Prado, V. } \\
(2017)\end{array}$ & $\begin{array}{l}\text { Formación para mediadores } \\
\text { en habilidades comunicativas } \\
\text { y emocionales para mejorar su } \\
\text { intervención y prevenir el acoso } \\
\text { escolar. }\end{array}$ & $\begin{array}{l}\text { Las habilidades emocionales tiener } \\
\text { que ver con la distancia entre el } \\
\text { estímulo y la manera de responder, } \\
\text { así como también regular la } \\
\text { respuesta afectiva. }\end{array}$ \\
\hline & & \\
\hline
\end{tabular}

Diferentes autores coinciden en aseverar que la empatía es necesaria en la mediación (Caravaca y Sáez, 2013; Caurín, Chalet y Martínez, 2009; Cava, 2009; Cuesta et al., 2017; García, Bonet y Mondragón, 2018; Lorente y Torrego, 2017; Lozano, Gutiérrez y Martínez, 2018; Lungman, 1996; Ortega y Del Rey, 2006; Sánchez y Gonzáles, 2017; Turk, 2018).

La empatía es entendida como la capacidad para comprender las emociones que surgen en cada una de las partes (García et al., 2018); si la persona siente que quien le escucha entiende su estado emocional, se establece una relación de ayuda y, por lo tanto, esta actitud permitirá el avance de la mediación (Lorente y Torrego, 2017). Pero en mediación no se trata únicamente de que el mediador comprenda los sentimientos y situaciones de las partes, sino que sea hábil para facilitar que los consultantes puedan entenderse entre ellos (Sánchez y Gonzáles, 2017).

La empatía y la actitud de ayuda están relacionadas con la sensibilidad ante los conflictos (Cuesta et al., 2017; Lungman, 1996). Este aspecto hace referencia a la habilidad de saber reconocer las emociones y sentimientos positivos como negativos que fluyen en la sesión, entre los que se encuentran el odio, la ira, el miedo, el entusiasmo, la esperanza. Esto para que el mediador visualice las consecuencias de las emociones sobre el conflicto (Ibarrola et al., 2017). Ser sensible no significa dejarse llevar, sino que implica la capacidad para ofrecer distancia entre lo que está pasando y la manera de responder (Cáceres et al., 2017). Pero no solo se trata de reconocer las emociones en los 
demás, sino también en su propia persona, es decir ser consciente de las propias emociones (Olmos et al., 2017).

A su vez la conciencia y la sensibilidad llevan a la regulación de las respuestas emocionales propias y de las personas en conflicto (Cáceres et al., 2017), en función de reducir la tensión (Medina, 2015) y evitar actuar de forma inapropiada (Sánchez y Gonzáles, 2017). La regulación incluye también una alta dosis de tolerancia ante los sentimientos de los demás, a la frustración y la templanza para postergar las recompensas inmediatas (Ortega y Del Rey, 2006; Romero et al., 2017).

Tabla 3. Principales aportes realizados a la dimensión Habilidades para la Comprensión y Gestión del Conflicto (CGC).

\begin{tabular}{lll}
\hline Autor/año & Título/tipo de documento & Aportes a la dimensión \\
\hline Lungman, S. & La mediación escolar & Evaluación de los intereses y \\
& necesidades, inventariar opciones, \\
(1996). & Capítulo de libro. & recentrar y re-enmarcar, ensayar la \\
& & realidad, parafraseo, negociación, \\
& permanecer neutral, fijación de metas, \\
& identificación de los puntos de agenda \\
& y ordenamiento. \\
\hline
\end{tabular}

\begin{tabular}{llll}
\hline Prada, J. & y & La mediación como estrategia de & b) \\
López, J. & $\begin{array}{l}\text { resolución de conflictos en el ámbito } \\
\text { escolar. }\end{array}$ & $\begin{array}{l}\text { preguntas abiertas y cerradas, así como } \\
\text { también resaltar intereses comunes. }\end{array}$
\end{tabular}

(2008).

Artículo de reflexión.

Sánchez, F. y Los programas de mediación escolar Habilidades de pensamiento creativo

Gonzáles, E. como herramientas para la promoción de indispensables para buscar soluciones,

(2017) unas relaciones de pareja saludables en y de pensamiento crítico presentes en la adolescencia. el análisis del conflicto y la búsqueda

Artículo de reflexión. de soluciones.

\begin{tabular}{lll}
\hline Cava, J. & La utilidad de la mediación como & El conflicto interpersonal, concepto y \\
(2009). & $\begin{array}{l}\text { estrategia de resolución y prevención de } \\
\text { conflictos. }\end{array}$ & formas de afrontarlo.
\end{tabular}

Artículo de reflexión.

\begin{tabular}{|c|c|c|}
\hline $\begin{array}{l}\text { Ortega, R. y } \\
\text { Rey, R. } \\
\text { (2006). }\end{array}$ & $\begin{array}{l}\text { La mediación escolar en el marco de } \\
\text { la construcción de la convivencia y } \\
\text { prevención de la violencia. } \\
\text { Artículo de reflexión. }\end{array}$ & $\begin{array}{l}\text { Comprensión de la naturaleza del } \\
\text { conflicto. }\end{array}$ \\
\hline $\begin{array}{l}\text { Calvo, P. y } \\
\text { García, A. } \\
\text { (2004). }\end{array}$ & $\begin{array}{l}\text { La mediación: técnicas de resolución de } \\
\text { conflictos en contextos escolares. } \\
\text { Artículo de reflexión. }\end{array}$ & $\begin{array}{l}\text { El conflicto y sus elementos, la } \\
\text { mediación, fases que lo componen y } \\
\text { objetivos. }\end{array}$ \\
\hline
\end{tabular}


Cuesta, M., et El educador social en la enseñanza

al.

(2017). secundaria. La mediación escolar como alternativa de resolución de conflictos.

Creatividad en la búsqueda de

soluciones, uso de un protocolo de actuación.

Artículo de reflexión.

Romero, L., Mediación escolar en el modelo

Alamilla, M. educativo para la educación obligatoria

y García, J. en México.

Artículo de reflexión.

García, L., Bo Significado y sentido de la mediación

Bonet, R. y escolar desde la perspectiva del

Mondragón, alumnado mediador de secundaria.

J. (2018).

Artículo de investigación.

Olmos, S., Competencias profesionales en

Torrecilla, E. y resolución de conflictos: Eficacia de un

Rodríguez, M. programa para la mejora competencial. (2017).

Artículo de investigación.
Reconocer la reciprocidad en el conflicto.

\section{Capacidad de reflexión acerca de los diferentes modos en que un conflicto puede ser solucionado.}

Para la resolución de conflictos es preciso entender que es parte circunstancial de la vida en sociedad; ser capaz de establecer diferencias con conceptos como agresividad y violencia.

\section{Capacidad para generar diversas} propuestas de acuerdo entre las partes.

Se necesita la filosofía de la mediación, el conocimiento de estrategias para la resolución de conflictos, aprendizaje práctico a través del modelaje de situaciones.

Turk, Fulya Evaluation of the effects of conflict Habilidad de resolución de problemas,
resolution, peace education and peer (2018). mediation: a meta-analysis study. lluvia de ideas o creación de consenso.

Artículo de reflexión.

\begin{tabular}{|c|c|c|}
\hline $\begin{array}{l}\text { Ceviker, S., } \\
\text { Kagan, H., y } \\
\text { Akilly, M. } \\
\text { (2019). }\end{array}$ & $\begin{array}{l}\text { Examining the effects of negotiation } \\
\text { and peer mediation on student's conflict } \\
\text { resolution and problem-solving skills. } \\
\text { Artículo de investigación. }\end{array}$ & $\begin{array}{l}\text { Reconocer la naturaleza del conflicto, } \\
\text { uso de estrategias de resolución. }\end{array}$ \\
\hline $\begin{array}{l}\text { Lozano, A., } \\
\text { Gutiérrez, P. } \\
\text { y Martínez, R. } \\
\text { (2018). }\end{array}$ & $\begin{array}{l}\text { La mediación educativa como cultura de } \\
\text { paz. } \\
\text { Artículo de reflexión. }\end{array}$ & $\begin{array}{l}\text { La mediación proporciona valores } \\
\text { de la cultura de paz y no violencia, } \\
\text { el respeto al otro, la cooperación y la } \\
\text { responsabilidad. }\end{array}$ \\
\hline
\end{tabular}


Lorente, I. y Percepción del alumnado y profesorado Torrego, J. sobre un programa de mediación entre iguales.
Capacidad de reflexión versus obrar de un modo impulsivo.

(2017).

Artículo de investigación.

\begin{tabular}{|c|c|c|}
\hline $\begin{array}{l}\text { Caurín, C., } \\
\text { Marco, N. y } \\
\text { Martínez, J. } \\
\text { (2009). }\end{array}$ & $\begin{array}{l}\text { Formación en convivencia y mediación: } \\
\text { una propuesta desde la educación } \\
\text { emocional. } \\
\text { Artículo de reflexión. }\end{array}$ & $\begin{array}{l}\text { La mediación está basada en la } \\
\text { educación social y moral. }\end{array}$ \\
\hline $\begin{array}{l}\text { Caravaca, C. } \\
\text { y Sáez, J. } \\
\text { (2013). }\end{array}$ & $\begin{array}{l}\text { La mediación herramienta para la } \\
\text { gestión de conflictos en la escuela. } \\
\text { Artículo de reflexión. }\end{array}$ & bajar tensiones. \\
\hline $\begin{array}{l}\text { Medina, M. } \\
\text { (2015). }\end{array}$ & $\begin{array}{l}\text { Mediación entre pares en las escuelas } \\
\text { públicas: una alternativa para la solución } \\
\text { de conflictos. } \\
\text { Artículo de reflexión. }\end{array}$ & $\begin{array}{l}\text { El mediador entiende sus propios } \\
\text { conflictos y sabe cómo manejarlos, } \\
\text { ayuda a otros y crea soluciones. }\end{array}$ \\
\hline $\begin{array}{l}\text { Zambrano, R. } \\
\text { (2015). }\end{array}$ & $\begin{array}{l}\text { Implantación de un programa de } \\
\text { mediación escolar. } \\
\text { Artículo de reflexión. }\end{array}$ & $\begin{array}{l}\text { Capacidad para validar las } \\
\text { perspectivas e integrarlas para generar } \\
\text { una visión completa. }\end{array}$ \\
\hline
\end{tabular}

Semejante a lo que ocurre en la dimensión habilidades para la conciencia y regulación emocional, los autores aluden a aspectos complementarios, en donde se aprecian coincidencias. Una de ellas es la necesidad que tiene el mediador de realizar una lectura y comprensión adecuada del conflicto (Calvo y García, 2004; Cava, 2009; Ceviker, 2019; García et al., 2018; Medina, 2015; Ortega y Del Rey, 2006; Olmos et al., 2017). Esto significa identificar los intereses y necesidades de las partes (Lungman, 1996), reconocer la reciprocidad del conflicto (Romero et al., 2017), identificar sus elementos (Calvo y García, 2004), saber que es parte circunstancial de la vida en sociedad, por lo tanto, difiere de la agresividad y la violencia (Olmos et al., 2017). El conflicto se lee y entiende en el contexto de una filosofía de la mediación (Díaz et al., 2015), fundamentada en la educación social y moral (Caurín et al., 2009) motivada por el análisis (Sánchez y Gonzáles, 2017) axiológico de valores como la cultura de paz, la no violencia, el respeto al otro, al., 2018). Es preciso anotar que el mediador no solo trata de ayudar a otros a resolver sus conflictos sino también requiere entender $y$ manejar los suyos (Medina, 2015), por tanto, deberá mostrar capacidad de reflexión, en lugar de actuar de modo impulsivo (Lorente y Torrego, 2017).

Otro aspecto que se reconoce, es que el horizonte ético dirige el modo de gestionar los conflictos; este aspecto es implícito para la búsqueda de soluciones, invención de opciones, fijar metas, identificar, ordenar los puntos de la agenda, usar un protocolo de actuación (Cuesta et al., 2017; Lungman, 1996; Sánchez y Gonzáles, 2017), las destrezas para realizar preguntas abiertas, resaltar los intereses comunes, emplear estrategias para lograr el consenso y reducir las tensiones (Caravaca y Sáez, 2013; Caycedo y Coconubo, 2016; Prada y López, 2008; Turk, 2018). 
Tabla 4. Principales aportes realizados a la dimensión habilidades para facilitar la comunicación (FC)

\begin{tabular}{|c|c|c|}
\hline Autor & Título/Tipo de documento & Aportes a la dimensión \\
\hline $\begin{array}{l}\text { Lungman, S. } \\
\text { (1996). }\end{array}$ & $\begin{array}{l}\text { La mediación escolar } \\
\text { Capítulo de libro. }\end{array}$ & $\begin{array}{l}\text { Habilidad de escuchar, desarrollo } \\
\text { de confianza y entendimiento, } \\
\text { autoridad, compartir información. }\end{array}$ \\
\hline $\begin{array}{l}\text { Prada, J. y } \\
\text { López, J. } \\
\text { (2008). }\end{array}$ & $\begin{array}{l}\text { La mediación como estrategia de resolución } \\
\text { de conflictos en el ámbito escolar. } \\
\text { Artículo de reflexión. }\end{array}$ & $\begin{array}{l}\text { c) Mantener las normas de } \\
\text { forma asertiva, controlar el lenguaje } \\
\text { corporal. }\end{array}$ \\
\hline $\begin{array}{l}\text { Sánchez, F. y } \\
\text { Gonzáles, E. } \\
\text { (2017). }\end{array}$ & $\begin{array}{l}\text { Los programas de mediación escolar como } \\
\text { herramientas para la promoción de unas } \\
\text { relaciones de pareja saludables en la } \\
\text { adolescencia. } \\
\text { Artículo de reflexión. }\end{array}$ & $\begin{array}{l}\text { Ser capaces de comunicarse con } \\
\text { las partes de forma apropiada y } \\
\text { productiva durante el proceso de la } \\
\text { mediación. }\end{array}$ \\
\hline $\begin{array}{l}\text { Cava, J. } \\
\text { (2009). }\end{array}$ & $\begin{array}{l}\text { La utilidad de la mediación como estrategia } \\
\text { de resolución y prevención de conflictos. } \\
\text { Artículo de reflexión. }\end{array}$ & $\begin{array}{l}\text { Habilidades de comunicación y } \\
\text { escucha activa. }\end{array}$ \\
\hline
\end{tabular}

Ortega, R. y La mediación escolar en el marco de la Capacidad de diálogo y escucha

Rey, R. $\quad$ construcción de la convivencia y prevención activa.

de la violencia.

(2006).

Artículo de reflexión.

Calvo, P. y La mediación: técnicas de resolución de

García, A. conflictos en contextos escolares.

Habilidades para una comunicación eficaz.

(2004). Artículo de reflexión.

Cuesta, M., et El educador social en la enseñanza Escucha activa, habilidades de

al. secundaria. La mediación escolar como comunicación verbal y no verbal.

(2017). alternativa de resolución de conflictos.

Artículo de reflexión.

Pulido, R. et Análisis de las habilidades de los alumnos Dentro de las habilidades de

al. mediadores como clave del éxito de la escucha activa están las técnicas:

(2015). mediación escolar. preguntas abiertas, resumir información, reflejar sentimientos, parafrasear y mensajes yo.

Hernández, La mediación en la resolución de conflictos. Escucha activa y capacidad de M. (2003). Artículo de investigación. diálogo.
Romero, L., Mediación escolar en el modelo educativo
Capacidad de diálogo.
Alamilla, M. para la educación obligatoria en México.
y García, J. (2017).
Artículo de reflexión. 
García, L., Bo Significado y sentido de la mediación

Escuchar a los demás.

Bonet, R. y escolar desde la perspectiva del alumnado

Mondragón, mediador de secundaria.

J. (2018).

Artículo de investigación.

\begin{tabular}{|c|c|c|}
\hline $\begin{array}{l}\text { Olmos, S., } \\
\text { Torrecilla, E. y } \\
\text { Rodríguez, M. } \\
\text { (2017). }\end{array}$ & $\begin{array}{l}\text { Competencias profesionales en resolución } \\
\text { de conflictos: Eficacia de un programa para } \\
\text { la mejora competencial. } \\
\text { Artículo de investigación. }\end{array}$ & $\begin{array}{l}\text { Ser competente en la comunicación } \\
\text { verbal y no verbal. }\end{array}$ \\
\hline $\begin{array}{l}\begin{array}{l}\text { Caycedo y } \\
\text { Cocunubo. }\end{array} \\
(2016) \text {. }\end{array}$ & $\begin{array}{l}\text { La mediación como una solución alternativa } \\
\text { de la violencia escolar. } \\
\text { Artículo de investigación. }\end{array}$ & $\begin{array}{l}\text { Capacidad de persuasión a la hora } \\
\text { de tomar decisiones con escasa } \\
\text { información. }\end{array}$ \\
\hline $\begin{array}{l}\text { Turk, F. } \\
\text { (2018). }\end{array}$ & $\begin{array}{l}\text { Evaluation of the effects of conflict } \\
\text { resolution, peace education and peer } \\
\text { mediation: a meta-analysis study. }\end{array}$ & $\begin{array}{l}\text { Habilidad de escucha activa y } \\
\text { discurso asertivo. }\end{array}$ \\
\hline
\end{tabular}

Ceviker, S., et Examinar los efectos de la mediación y Comunicación constructiva.

al. negociación de pares en la resolución

(2019). de conflictos de los estudiantes y las

habilidades de solución de problemas.

Artículo de investigación.

Lozano, A., et La mediación educativa como cultura de Escucha activa, asertividad.

al. (2018). paz.

Artículo de reflexión.

Lorente, I. y Percepción del alumnado y profesorado Habilidades de escucha.

Torrego, J. sobre un programa de mediación entre

(2017). iguales.

Artículo de investigación.

Caravaca, C. La mediación herramienta para la gestión Hábil comunicador y facilitador

y Sáez, J. de conflictos en la escuela. del diálogo, persuasivo y lleno de fuerza.

(2013). Artículo de reflexión.

Medina, M. Mediación entre pares en las escuelas $\quad$ Escucha los puntos de vista de

(2015) públicas: una alternativa para la solución de las otras personas, trata a los conflictos. demás con respeto, protege la confidencialidad de la información, Artículo de reflexión. se comunica con claridad.

Zambrano, R. Implantación de un programa de mediación El mediador debe ser un escolar. excelente observador y dominar la (2015) Artículo de reflexión. comunicación verbal y no verbal. 


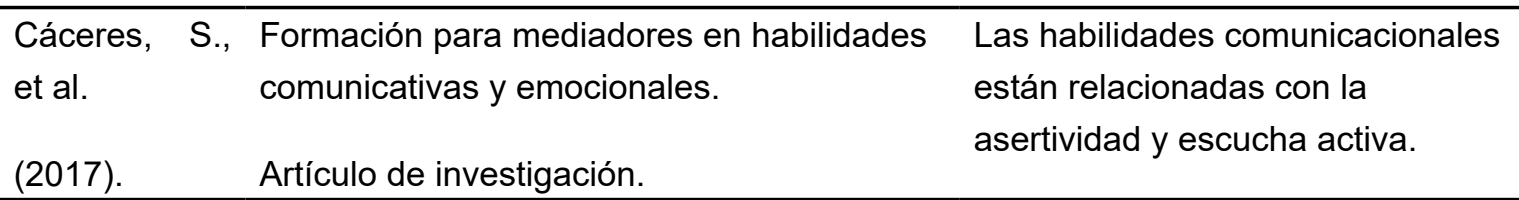

Autores como Calvo y García (2004), Caravaca y Sáez (2013), Cava (2009), Cáceres et al. (2017), Ceviker (2019), Cuesta et al. (2017), Olmos et al. (2017), Sánchez y Gonzáles (2017), Turk (2018) y Zambrano (2015) coinciden en reconocer la importancia de las habilidades para facilitar la comunicación en la mediación. Dentro de las más importantes está la capacidad de escuchar con respeto los puntos de vista de las demás personas (Cáceres et al., 2017; Cava, 2009; Cuesta et al., 2017; García et al., 2018; Hernández, 2003; Lorente y Torrego, 2017; Lozano et al., 2018; Lungman, 1996; Medina, 2015; Ortega y Del Rey, 2006; Pulido et al., 2015; Turk, 2018). También el compromiso con la confidencialidad de la información (Medina, 2015), lo que abre el camino a la comunicación constructiva y al clima de confianza (Ceviker et al., 2019; Lungman, 1996), donde se mantiene las normas (Prada y López, 2008). Tan importante como escuchar, es comunicarse de forma clara, apropiada y productiva con las partes (Medina, 2015; Sánchez y Gonzáles, 2017), ser persuasivo (Caravaca y Sáez, 2013; Caycedo y Coconubo, 2016; Medina, 2015).

\section{DISCUSIÓN}

El objetivo de este estudio fue identificar los elementos teóricos que constituyen la formación de habilidades socio-emocionales para la mediación escolar. Esta revisión sistemática, reconoce que el abordaje académico del concepto se hace de manera general y son escasos los estudios que concretan la mediación al ámbito escolar. No se reconocen estudios o aportes que aborden explícitamente lineamientos para la formación de habilidades socio-emocionales para la mediación escolar, por lo que este aspecto se reconoce importante como resultado de este estudio. También se observa que las perspectivas de los diferentes autores son complementarias, enuncian aspectos semejantes con diferentes palabras y utilizan distintas acepciones, por lo que las posturas se aprecian dispersas.

Respecto a la producción científica, el análisis por países resalta el aporte significativo de España al cuerpo teórico de conocimiento sobre el concepto, encontrándose una diferencia notoria respecto a los países de América Latina. Por ejemplo, Colombia y Argentina alcanzan solo dos producciones en 25 años, mientras que México tan solo una en el mismo periodo de tiempo; el resto de los países de la región al parecer no han participado con aportes a la consolidación de la teoría sobre las habilidades para la mediación escolar. Esto sugiere que las sociedades latinoamericanas requieren fomentar la investigación en la temática ya que, sus condiciones sociales, culturales y económicas, urgen la construcción de una cultura de paz en la escuela y la posibilidad de enseñar formas alternativas de resolver conflictos.

De otro lado, los hallazgos también indican que el interés científico por las habilidades para la mediación escolar se mantuvo constante sin superar las dos producciones anuales entre 1995 y 2014. Desde el 2015 el número de publicaciones aumenta, lo que sugiere que la comunidad académica reconoce la necesidad de fortalecer la investigación en dicha temática dada su relevancia en los procesos de formación y consolidación de los centros de mediación en las escuelas.

A partir de la revisión sistemática realizada, se reconoce que las "habilidades socioemocionales para la mediación escolar" hacen referencia a las cualidades personales que 
facilitan el proceso de la mediación escolar y pueden posibilitar el cambio de la perspectiva del conflicto de manera más rápida, en cada una de las partes. Algunos investigadores refieren que a las habilidades para resolver conflictos (Aznar et al., 2018; Brewer, 1998), son iguales o similares a las habilidades para la mediación.

Los resultados permiten proponer tres lineamientos, categorías o dimensiones para la formación de habilidades socio-emocionales para la mediación escolar: 1) conciencia y regulación emocional: esto es la capacidad del mediador para identificar las emociones que fluyen en las partes y en sí mismo con el objeto de reducir la tensión; 2) gestión y comprensión del conflicto: es la destreza con la que el mediador lee y analiza los argumentos y discursos de las partes, en búsqueda de una solución pacífica que satisfaga sus intereses; y 3 ) habilidades para facilitar la comunicación; es decir, la formación para que, a partir de los argumentos escuchados y analizados, el mediador pueda expresarse de una manera adecuada y generar conversaciones productivas en las partes.

La anterior categorización es coherente con el modelo de López (2016), que las delimita de acuerdo con el canal de respuesta: habilidades emocionales, cognitivas y de conducta; no obstante, asumen una orientación distinta pues se considera más oportuno delimitarlas desde los procesos específicos que favorecen el logro de la mediación. En ese sentido nuestra propuesta amplía lo formulado por Johnson et al. (1996) al considerar el papel relevante de las emociones. El mencionado autor las distingue en términos de comunicación, asertividad y mediación. Es preciso resaltar que la apuesta conceptual va en línea con Méndez (1994 citado en Serrano y Méndez, 1999) quién las destaca como cualidades personales, diferenciándose en la medida en que no se considera el entrenamiento en sí mismo como una habilidad.
De manera particular, las habilidades para la conciencia y regulación emocional aluden a la sensibilidad ante los conflictos, esto implica reconocer, designar, expresar y evaluar la intensidad de las emociones, así como los sentimientos positivos y negativos que fluyen en el encuentro del mediador con las partes, de tal manera que sea posible reducir la tensión de las personas en conflicto y evitar actuar de forma inapropiada, motivados por los impulsos. Es en este punto en dónde cobra valor la capacidad de entender la perspectiva de las partes en aras de promover el aumento de la confianza, así como la reflexión sobre las consecuencias de los actos (Caurín et al., 2009; Caycedo y Coconubo, 2016; Lungman, 1996; Olmos et al., 2017).

La segunda dimensión, habilidades para la comprensión y gestión del conflicto, hace alusión a la capacidad para identificar las creencias, necesidades e intereses propios y de las partes, reconocer la reciprocidad en el conflicto y analizar los detalles. Esta dimensión se sustenta en una filosofía de la mediación, que no solo incluye los conocimientos básicos sobre el conflicto, sino también el valor agregado del autocuidado y el cuidado del otro, ejercicio práctico de los valores humanos como cultura de paz, la comprensión de las normas, la no violencia, el respeto por el otro, la cooperación y la prosocialidad (Lozano et al., 2018). Así, el marco axiológico dirige las formas de entender el conflicto y también la facilidad para gestionarlo, desde una postura reflexiva que identifica y ordena los puntos de la agenda, usa un protocolo de actuación, fija metas, emplea pasos, realiza sugerencias, clarifica asuntos importantes, y resalta los intereses comunes para buscar e identificar opciones que permitan lograr el consenso (Serrano et al., 2007).

Finalmente, las habilidades para facilitar la comunicación aluden a la capacidad de escuchar con respeto los diversos puntos de vista, demostrar compromiso con la confidencialidad 
de la información, la posibilidad de mantener una actitud atenta en el encuentro y la destreza para comunicarse de forma apropiada, persuasiva y productiva con las partes (Caravaca y Sáez, 2013; Medina, 2015). La comunicación del mediador, que es verbal, debe reflejar seguridad y firmeza; por lo que el uso de un tono de voz conciliador pero aplacado, permitiría un mejor proceso. Complementariamente un mediador debe desarrollar la habilidad para hacer pedidos claros, responder creativamente a la crítica, como también emplear modos proxémicos no verbales conciliadores no amenazantes (López, 2016; Serrano et al., 2007; Zambrano, 2015).

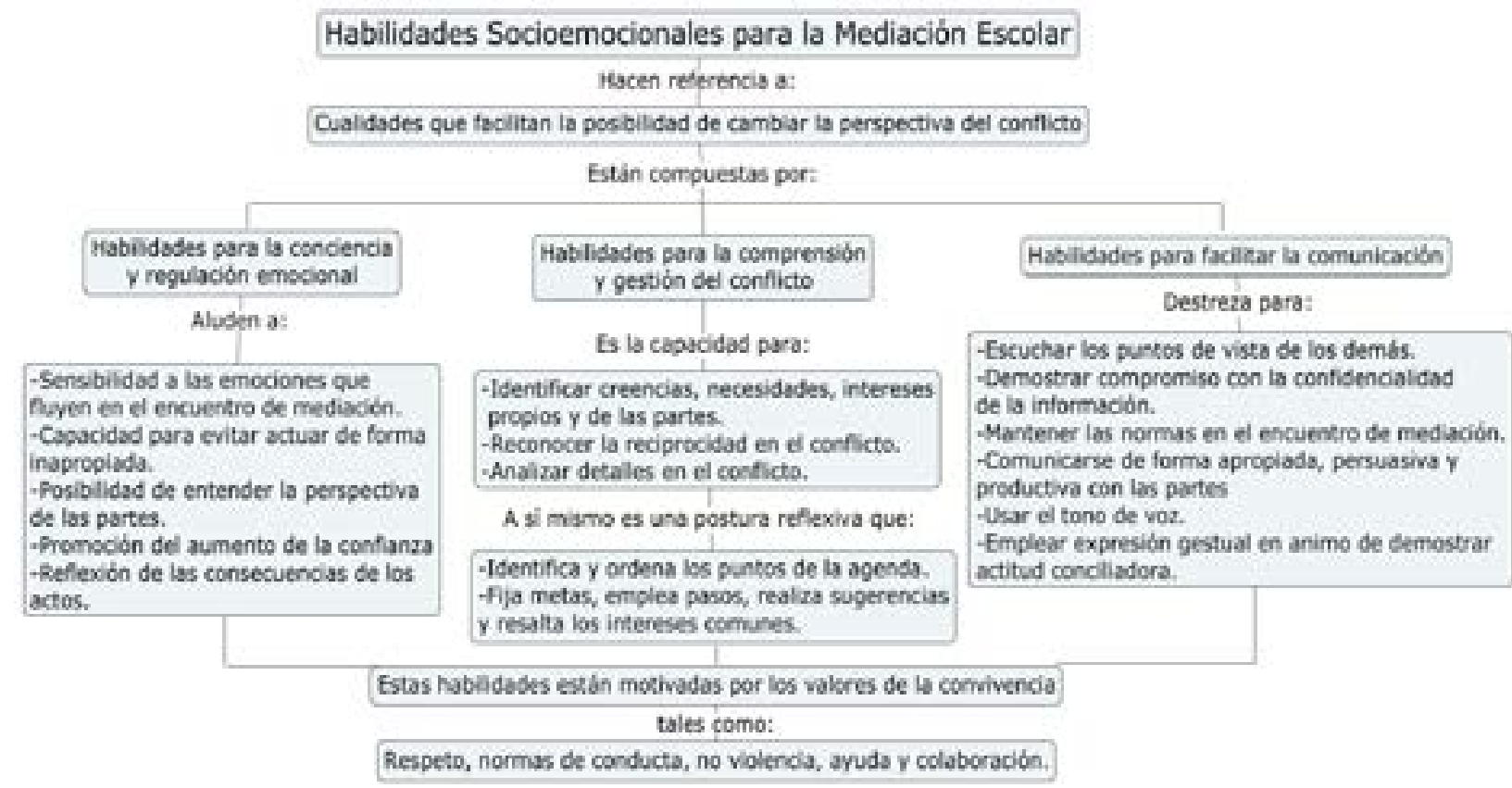

Figura 4. "Las habilidades socio-emocionales para la mediación escolar" y sus dimensiones.

Los análisis presentados alrededor del constructo "formación de habilidades socioemocionales para la mediación escolar", consolidados en la figura cuatro y expuestos en este estudio, aportan al desarrollo de futuras líneas de investigación relacionadas con: 1) Creación de instrumentos de medición, 2) Selección de mediadores escolares; 3 ) diseño de programas de formación de mediadores escolares.
Las limitaciones de este estudio están relacionadas con la escasez de datos empíricos para la formulación de meta-análisis, y la no inclusión de otras bases de datos. No obstante, los hallazgos representan una oportunidad para avanzar en la consolidación de la teoría sobre la formación de habilidades socio-emocionales para la mediación escolar. 


\section{REFERENCIAS BIBLIOGRÁFICAS}

Acosta, R. \& Arboleda, A. (2019). La educación en mediación escolar como escenario de formación ciudadana. Revista Espacios, Vol. 40, №. 21, 2018, págs. 1-8.

Aznar, J., Castillo, L. \& Duplá, T. (2018). Mediation techniques in secondary education should take into account gender differences for enhanced effectiveness: evidence from secondary schools in Catalonia. Athens Journal of Education, Vol. 5, №. 3, págs. 247-259.

Benavides, M. (2013). Tipología de la conflictividad escolar en las instituciones educativas de Pasto. [Trabajo final de especialización, Universidad de NariñoColombia].

Bermúdez, R. \& Rodríguez, M. (2019). La inconsistencia psicológica del concepto pedagógico de habilidad profesional. Revista cubana de educación superior, Vol. 38, № 1 , págs. 1-26.

Betancourth, S., Carvajal, G. \& Figueroa, M. (2017). Caracterización de los roles de agresión en un colegio público de San Juan de Pasto. Psicoespacios, Vol. 11, №. 19, 2016, págs. 84-98.

Brewer, B. (1998). The effects of conflict mediation training on attitudes toward conflict and interpersonal problemsolving strategies on middle school. [Doctoral thesis, Virginia Polytechnic Institute and State University-EEUU].

Cabrera, C., García, D. \& Tabares, C. (2016). Concepciones de conflicto escolar: un estudio del conflicto desde la perspectiva de los estudiantes. Revista de Investigaciones Universidad del Quindío, Vol. 28, №. 2, 2015, págs. 2230.
Cáceres, S., Giménez, M. \& Prado, V. (2017). Formación para mediadores en habilidades comunicativas $y$ emocionales para mejorar su intervención y prevenir el acoso escolar. Calidad de vida y salud, Vol. $10, \mathrm{~N}^{\circ} .1$, págs. 2-9.

Calvo, P. \& García, A. (2004). La mediación: técnica de resolución de conflictos en contextos escolares. Anuario de filosofía, psicología y sociología, Vol. 7 , págs. 35-48.

Candeias, M. \& Bartolo, S. (2016). La gravitación de la ética de la atención en la mediación: intervención social y escolar en las escuelas. Poiesis, Vol. 10, $\mathrm{N}^{\circ}$. 18, págs. 371-388.

Cano, R. \& Garrido, P. (2017). La mediación escolar y el desarrollo de la inteligencia emocional como alternativa en la transformación pacífica de conflictos en educación media superior. Revista CoPaLa, Vol. 2, Nº. 3, págs. 99-108.

Caravaca, C. \& Sáez, J. (2013). La mediación: Herramienta para la gestión de conflictos en la escuela. Revista de Educación Social, Vol. 16, págs. 1-16.

Carvajal, C., Urrea, P. \& Soto, M. (2012). La convivencia escolar en adolescentes de cinco municipios de sabana centro Departamento de Cundinamarca-Colombia. [Tesis de maestría, Universidad de la Sabana, Cundinamarca-Colombia].

Castro, A. (2013). Propuesta para la implementación de la mediación escolar como método alternativo de resolución de conflictos para la construcción de una convivencia pacífica en las instituciones educativas públicas de la ciudad de Pasto. [Trabajo final de 
especialización, Universidad de Nariño, Nariño-Colombia].

Caurín, C., Marco, N. \& Martínez, J. (2009). Formación en convivencia y mediación: una propuesta desde la educación emocional. Compartim revista de formación del profesorado, Vol. 4, págs. 1-9.

Cava, J. (2009). La utilidad de la mediación como estrategia de resolución y prevención de conflictos en el ámbito escolar. Información Psicológica, Vol. 95, págs. 15-26.

Caycedo, R. \& Cocunubo, N. (2016). La mediación como solución alternativa de la violencia escolar. Investigaciones Andinas, Vol. 18, № 33 , págs. 17291749 .

Ceviker, S. Keskin, H. y Akilli, M. (2019). Examining the effects of negotiation and peer mediation on student's conflict resolution and problem-solving skills. International Journal of Instruction, Vol. $12, \mathrm{~N}^{\circ} .3,2018$, págs. 717-730.

Chaux, E. \& Velásquez, A. (2008). Violencia en los colegios de Bogotá: contraste internacional y algunas recomendaciones. Revista Colombiana de Educación, № .55 , págs. 14-37.

Cuesta, M., Martínez, M., Cuesta, J., Sánchez, S. \& y Orozco, M. (2017). El educador social en la enseñanza secundaria. La mediación escolar como alternativa de resolución de conflictos. Ehquidad International Welfare Policies and Social Work Journal, Vol. 7, págs. 145-174.
Daunic, A., Stephen, S., Robinson, R., Miller, D. \& Landry, K. (2000). School-wide conflict resolution and peer mediation programs: experiences in three middle schools. Intervention in school and clinic, Vol. 36, $\mathrm{N}^{\circ}$. 2, págs. 94-100.

De Armas Hernández, M. (2003). La mediación en la resolución de conflictos. Educar, págs. 125-136.

Díaz, M., Luján, I., Rodríguez, H. \& Rodríguez, J. (2015). Análisis de la gestión e implementación en mediación en el ámbito escolar. International Journal of Developmental and Educational Psychology, Vol. 1, №. 1, págs. 275-284.

Dorsch, F., Bergius, R. \& Ries, H. (1996). Diccionario de Psicología. Editorial Herder.

García, L., Bonet, R., \& Boqué, M. (2015). Percepción del alumnado de educación secundaria sobre la mediación escolar en Castellón y Valencia. Revista Complutense de Educación, Vol. 28, Nº. 2, págs. 537-554.

García, L., Bonet, R. \& Mondragón, J. (2018). Significado y sentido de la mediación escolar desde la perspectiva del alumnado mediador de secundaria. REOP, Vol. 29, №. 3, págs. 79-93.

Gonzáles, M. (2018). Educar para la paz, una tarea de todos. Mediación escolar. El cotidiano, Vol. $33, \mathrm{~N}^{\circ}$. 208, págs. 67-77.

Hermosilla, L. (2015). Programa de mediación escolar y formación de alumnos mediadores en el IESO Canal de Castilla. [Trabajo fin de máster, Universidad de Valladolid, Valladolid-España]. 
Hernández, M. (2003). La mediación en la resolución de conflictos. Educar, $\mathrm{N}^{\circ}$. 32, págs. 135-136.

Holaday, L. (2002). Stage development theory: A natural framework for understanding the mediation process. Negotiation Journal, Vol.18, №. 3, págs. 191-210.

Ibarrola, S. \& Iriarte, C. (2014). Desarrollo de las competencias emocional y sociomoral a través de la mediación escolar entre iguales en educación secundaria. Revista Qurriculum, Vol. 27, págs. 9-27.

Ibarrola, S., Iriarte, C. \& Aznárez, M. (2017). Aprendizaje emocional autoconsciente durante procedimientos de mediación en el contexto escolar. Electronic Journal of Research in Educational Psychology, Vol. 15, № 1 , págs. 75-105.

Johnson, D., Johnson, R., Mitchell, J., Cotten, B., Harris, D. \& Louison, S. (1996). Effectiveness of Conflict Managers in an Inner-City Elementary School. The Journal of Educational Research, Vol. $89, N^{\circ} 5$, págs. $280-285$.

Leonov, N. y Glavatskikh, M. (2017). Changing the image of a conflict situation while training school students in mediation skills. Psychology in Russia, Vol. 10, $\mathrm{N}^{\circ}$. 2, 2015, págs. 165-178.

López, M. (2016). Formación de formadores y mediadores escolares con análisis transaccional. European Scientific Journal. Special Edition, págs. 248-260.

Lorente, I. \& Torrego, J. (2017). Percepción del alumnado y profesorado sobre un programa de mediación entre iguales. Qualitative Research in Education, Vol. 6, N² , págs. 214-238.
Lozano, A., Gutiérrez, P. \& Martínez, R. (2018). La mediación educativa como cultura de paz. Revista de Cultura de Paz, Vol. 2, págs. 125-145.

Lungman, S. (1996). La mediación escolar. Lugar Editorial.

Medina, M. (2015). Mediación de pares en las escuelas públicas: una alternativa para la solución de conflictos. Revista Griot, Vol. 8, № . 1, págs. 85-103.

Moher, D., Shamseer, L., Clarke, Mike., Ghersi, D., Liverati, A., Petticrew, M., Shekelle P. \& Stewart, L. (2015). Preferred reporting items for systematic review and metaanalysis protocols (PRISMA-P). Systematic reviews, Vol. $4, N^{\circ} .1$.

Montero, I. \& León, O. (2007). A guide for naming research studies in psychology. International Journal of Clinical and Health Psychology, Vol. 7, № .3 , págs. 847-862.

Olmos, S., Torrecilla, E. \& Rodríguez, M. (2017). Competencias profesionales en resolución de conflictos: eficacia de un programa para la mejora competencial. Revista Española de Orientación y Psicopedagogía, Vol. 28, $\mathrm{N}^{\circ}$. 3, págs. 25-42.

Ortega, R. \& Del Rey, R. (2006). La mediación escolar en el marco de la construcción de la convivencia y la prevención de la violencia. Revista de la Asociación de Inspectores de la Educación de España, Vol. 2.

Ortega, R., Maripangui, C., Ñacupil, M., Cabezas, H. \& Carafi E. (2007). Orientación de estratégicas para la formación de monitores en mediación de conflictos escolares. Santiago de Chile: Universidad de Chile. 
Pinto, E. (2017). Mediación escolar: un estudio de caso en Portugal. Centro de Investigación en Derecho Público Universidad de Montreal, págs. 1-8.

Portillo, M. (2017). Educación por habilidades: perspectivas y retos para el sistema educativo. Revista Educación, Vol. 41, $\mathrm{N}^{\circ} .2,2015$, págs. 1-13.

Prada, J. \& López, J. (2008). La mediación como estrategia de resolución de conflictos en el ámbito escolar. Documentación Social, Vol. 148, págs. 99-116.

Pulido, R., Fajardo, T., Pleguezuelos, L. \& De Gregorio, R. (2010). La mediación escolar en la comunidad de Madrid: Análisis del impacto de la formación en el profesorado y alumnado en el IES "Las Américas" de Parla. Revista de Mediación, Vol. 3, Nº . 6, págs. 32-43.

Pulido, R., Calderón, S., Seoane, G. \& Molina, B. (2015). Análisis de las habilidades de los alumnos mediadores como clave del éxito en la mediación escolar. Información psicológica, Vol. 110, N․ 2 , 2014, págs. 24-38.

Rolán, K., Martínez, M., Parada, V., Abilleira, A. \& Fariña F. (2017). Acoso escolar en primaria tras la formación en técnicas de mediación. Revista de estudios e investigación en psicología y educación, Vol. 2, págs. 82-86.

Romero, L., Alamilla, M. \& García, J. (2017). Mediación escolar en el modelo educativo para la educación obligatoria en México. International Journal of Humanities and Social Science Invention, Vol. 6, № . 7, págs. 37-42.
Sánchez, D. \& Gonzáles, E. (2017). Los programas de mediación escolar como herramientas para la promoción de unas relaciones de pareja saludables en la adolescencia. Revista española de orientación y psicopedagogía, Vol. 28, $\mathrm{N}^{\circ}$. 1, págs. $72-85$.

Serrano, G. \& Méndez, M. (1999). Las intervenciones de los mediadores. Revista de Psicología General y Aplicada, Vol. 52, №. 2, págs. 235-253.

Serrano, G., Lopes, C., Rodríguez, D., Mirón, L. (2007). Características de los mediadores y éxito de la mediación. Anuario de Psicología Jurídica, Vol. 16, No. 75-88.

Turk, F. (2018). Evaluation of the effects of conflict resolution, peace education and peer mediation: a meta-analysis study. International Education Studies, Vol. 11, $\mathrm{N}^{\circ}$. 1, págs. 25-43.

Turnuklu, A., Kacmaz, T., Gurler, S., Turk, F., Kalender, A., Zengin F. \& Sevkin, B. (2010). The effects of conflict resolution and peer mediation training on Turkish elementary school student's conflict resolution strategies. Journal of Peace Education, Vol. $7, \mathrm{~N}^{\circ} .1$, págs. 33-45.

Viana, M. \& López, I. (2015). Aportación de la mediación escolar a la igualdad y a la inclusión social. Revista nacional e internacional de educación inclusiva, Vol. 8, №. 1, págs. 14-26.

Villanueva, L., Usó, I. \& Serrano, J. (2013). Los programas de mediación entre iguales: una herramienta eficaz para la convivencia escolar. Apuntes de psicología, Vol. $31, \mathrm{~N}^{\circ}$. 2, págs. 165171. 
Vizcaíno, M. (2015). La formación para la convivencia: un reto para la gestión escolar. Espacio abierto cuaderno venezolano de sociología, Vol. $24, \mathrm{~N}^{\circ}$. 3,2014 , págs. 115-129.

Yvetta, G. and others. (1995). Effects of Peaceful Solutions Peer Mediation Training on Knowledge and Skills of Elementary Students. Meeting Papers, Ed 392553.

Zambrano, R. (2015). Implantación de un programa de mediación escolar. Vía Docente, Vol. 1, págs. 38-41. 